\title{
東拉西扯再談中日文化差異 \\ Let' $s$ turn a new chapter about the difference between Chinese and Japanese culture
}

\section{李 澤森 \\ 第一日語暨文化學校}

百里不同風, 千里不同俗, 習慣了以筷子吃飯的中國人, 看見印度人以手把飯搓成一團然後放入 口中的食相, 大多會覺得既不文明, 也不衛生。日本人也以筷子吃飯, 但不會像中國人般端起飯碗用 筷子把飯往口裡扒, 只會一團一團夾起來吃, 他們視扒飯為沒教飬, 這是習慣扒飯的中國人難以荷同 的。在日本, 二人對酶的時候, 只有到了熟不拘禮的地步才會自酌自飲, 一般來說, 互相給對方注酒 是基本禮儀, 只顧往自己的杯裡注酒, 反而是暗示對方不懂規矩, 對對方不敬。就是這樣子, 少許習 慣上的差異, 往往做成很大的誤解。

\section{1. 《地域性格》}

俗語說一方水土養一方人, 即使同是中國人或日本人, 不同地方的環境和傳統, 都會形成不同的 地域性格。

上世紀 80 年代初期, 中國經濟改革方興未艾, 日資企業大舉在中國投資, 當時在日資企業之間流 傳著很多對中國人性格描述的傳聞。其中一則傳聞是如果跟同是擁有一百萬元資金的北京人、上海人 或廣東人合作洽談生意, 北京人會如實告訴你他們的出資能力上限是一百萬元。但如果是上海人話, 他們會告訴你他們的出資上限是二百萬元。要是廣東人的話, 他們會告訴你他們的出資上限只是五十 萬元。這傳聞道出了北京人敦厚, 上海人進取和廣東人保守。雖然未必貼切, 但也算是對華北、華東 和華南三地中國人性格的描述。

日本人方面又如何呢? 據說, 如果東京人、大阪人和名古屋人一起吃飯, 在快吃完飯準備結賬之 際, 東京人會為怎樣才能在其餘兩人不察覺的情況下付三人的飯錢而坐立不安。大阪人則在盤算每個 人應該各自分攤多少。名古屋人卻在考慮怎麼向二人道謝。這譬喻也說出了關東人、關西人和中部人 性格截然不同。

\section{2. 《墨守成規・因時制宜》}

2008 年年初, 日本學習研究社 (日研) 推出的一款在中國製造的地球儀, 意料不及地在日本各大報 章揭起了一場不大不小的辯論。事緣是日研委託中國生產商製造了一批會說話的地球儀, 只要按一下 地球儀上的國家或地方, 地球儀就會說出有關地方的主要資料。問題出於有關台灣的部份, 原來有關 資料由原先的「國家首腦陳水扁給改為胡錦濤, 使用貨幣由新台幣給改為人民幣」, 日研方面解釋說 是應中國製造商的要求而不得不作出有關改動的, 但外間不少人認為這跟現實不符, 日研推出的是個 
李 澤森：東拉西扯再談中日文化差異

說謊的地球儀, 在興論壓力底下, 日研不得不宣布回收所有產品。一些學者以這次事例來分析東亞兩 大民族不同的處事作風, 日本人以法規為先, 堅守合約精神, 中國人則認為任何事情都應因時制宜。 中國人跟日本人洽談生意的時候, 常常指責日本人不懂靈活變通, 過於拘泥成法, 正由於中國人的秩 序意識和法規意識淡薄, 在商貿關係上動輯對人動之以情, 並強調萬事應隨機應變和互相妥協, 很多 時會以客觀條件發生變化為由, 要求修改合約上的一些條款, 這種處事方式往往令對方哭笑不得。 2011 年 8 月在深圳舉行的世界大學生運動會中, 大會臨時提早了游泳項目的比賽時間, 令不少參賽隊 伍錯過了有關比賽, 一些領隊向大會投訴, 但不獲受理, 大會發言人其後表示, 官方提供的時間表只 供參考, 賽程還得按實際情沉調整的。

\section{3. 《往自己臉上貼金 vs 謙遜は最大のうぬぼれ》}

名片又稱名刺, 是當今社交上不可缺少的道具。據考究, 名片最早出現於戰國時代, 是國與國互 派使者晉竭時的介紹文書, 早期稱「謁」, 唐朝時稱「名刺」, 至清朝時始稱「名片」。日本人使用 名片可追溯至江戶時代 (1603-1867)，那時多用作通報姓名或留言的便條。

名片的最大功能是讓對方認識自己, 所以除了自己的姓名, 還會印上所屬機關、職銜、地址、電 話及電郵等。在功利主義影響下, 中國人唯恐別人不知道自己擁有高學歷而喜歡在名片上加上個人的 學歷名銜, 例如甚麼 BA HK; MSC、PhD Leic、CertEd(TESL) HK、BA, Cert Ed, M Ed、BA Sc, MIMarE 之類, 看得讓人眼花潦亂。反之, 日本人鮮會往自己臉上貼金, 很少在名片上加上 $\mathrm{xx}$ 碩士或 $\mathrm{xx}$ 博士的銜頭。如果說日本人的謙虛是虛偽的話, 中國人在這方面會不會是心理學上所說的因過份自 卑而自大呢! 雖然這未必是修身名訓「滿招損, 謙受益」的最佳註腳, 但在名片這一小塊紙片上似乎 顯露了中國人和日本人迴異的心態。

據說香港某大學助理教授, 在榮升教授的一天起就吩咐下屬囑人別再以先生稱之而代之以教授。 也有曾任駐外大使的某駐港總領事, 喜歡別人以大使稱之以示高人一等。在這些個別例子裡, 虛榮心 似乎並沒有跨越國度而不同。

\section{4. 《Be considerate vs My way》}

上世紀末, 受矽谷文化影響, cyber-10ok 成為時尚, 背囊取代了傳統的公事包, 大行其道, 連西 裝革履的白領階級都背著背囊上班。時至今日, 背囊好像已經成為大多數香港人服装的一部份, 但跟 大部份日本人不一樣, 日本人在擠迫的地鐵或火車的車廂裡大多會考慮可能會妨礙別人而把背囊放在 地上或置於胸前, 反之, 很多香港人則我行我素, 對可能阻礙他人依然旁若無人地把背囊背在身上。

垃圾處理一向是不少大城市面對的難題, 傳統的處理方式不是埋在堆填區便是焚化, 這些處理方 式不單污染地下水源, 還產生大量好像二堅英等有害氣體。日本人很早便把垃圾分類, 而且教育工作 進度良好, 大多數人都樂意遵從政府呼籥, 將垃圾分類棄置, 在日本生活過的人對「ごみは分けて捨 てょう」這口號一定不會陌生。中國在處理垃圾方面比日本起步慢, 上世紀 80 年代之前都是露天堆放 而且是不會分類的。90 年代開始才興建垃圾處理場, 2002 年才開始提倡把垃圾分類棄置, 但效果不 
彰。會不會是中國人自少飬成了各家自掃門前雪, 不理他人瓦上霜的習慣跟日本人的「他人に迷惑を かけてはいけない」顧己及人的思維不同有關呢！

\section{5. 《冷暖感覺》}

香港地處亞熱帶, 夏天潮濕炎熱, 從前沒有空調, 一般靠在門前潑水或搖扇納涼。隨著空調裝置 日漸普及, 現在差不多所有室內地方都有冷氣裝置, 不少地方溫度低得令人打顫, 連習慣了寒冷天氣 的日本人也抵受不了, 甚至說香港的夏天太冷了。

暖氣機是日本冬天不能缺少的禦寒裝置, 商場、巴士、火車、酒店都有暖氣開放, 偏偏不少香港 人忍受不了, 甚至不喜歡這種非冷非暖的感覺, 曾經有過香港學生在當地民居留宿的時候, 因為覺得 室內的暖氣令他感到納悶而把窗戶打開, 翌日給戶主申斥了一頓。香港學生對受責感到莫名, 日本人 戶主則認為香港學生的行為令人費解。這大概是冷暖感覺上的文化衝突吧！

\section{6. 《政府・政庁》}

政府是治理和代表國家的最高行政機關, 在日本, 政府指包括負責行政的內閣、負責立法的國會 和負責司法的法院。管轄地方的只能稱「政庁」，所以，日本人對中國內地的「 $\times \times$ 省人民政府」、 $\lceil\times \times$ 鎮人民政府」等稱謂大惑不解, 誤以為中國像美國般實行聯邦制。曾經有初到香港的日本人對 辦理某些手續而被指示到九龍政府合署或沙田政府合署感到奇怪, 問為什麼香港政府之下還有九龍政 府、沙田政府, 這是習以為常的香港人為之語塞的。

\section{7. 《蒲松齡・柳田國男》}

似乎任何一個民族都信有鬼神存在, 中國人對鬼的定義一般是指死者的魂魄, 大都是怨氣化成, 沒有歸宿的遊魂野鬼。在日本, 鬼指山魅妖怪, 死者的魂魄稱為「幽霊」。

論語有: 子不語怪、力、亂、神, 又有: 務民之義, 敬鬼神而遠之, 可謂知矣的記載。儒家對鬼 魂是否存在似乎既不肯定也不否定。雖然如此, 傳統上中國人相信人死後會變成鬼, 含冤而死的人更 會化為庽鬼, 是以民間流傳著各式各樣的鬼故事, 蒲松齡在聊齊誌異中收集了不少有關狐、仙、鬼、 妖的傳說, 有描述好像「義鼠」、「小翠」、「庚娘」等報恩情節, 也有好像「陸判」、「畫皮」等 復仇故事。

在日本, 被視為三大怪談的「四谷怪談」、「皿屋敷」和「牡丹燈籠」都是描述枉死鬼魂復仇的 故事。另一方面, 柳田國男在遠野物語和遠野物語拾遗中收集了不少各地有關靈異的傳說, 好像具有 超能力的天狗、喜歡捉弄村民的河童、只有小孩子才看得見的精靈座敷童子、山人、神隱等。民間傳 說的百鬼夜行描述的則是只在晚間活動的妖怪世界。 


\section{8. 《謹小慎微・粗枝大葉》}

中國的微型雕刻技藝精湛, 舉世聞名, 中國人也精於物理幾何, 太空科技早已超英趕美, 所以不 能說中國人缺乏慎密的心思, 不過在生活層面, 中國人不少地方實在不如日本人般謹小慎微。好像到 書店購書的時候, 店員都會殷勤地給顧客買的書加上書套, 有了這一層書套, 私隱得以保護, 看書的 時候就用不著介意旁人窺測的目光了。

喬遷新居是一件喜事, 為免勞碌, 大多數人都會委託搬家公司代勞。中國的搬家公司講求效率, 搬運工人七手八腳就會把一整家的大小傢俱搬好。日本的搬家公司則強調無微不至的服務, 中國的搬 運工人只會在陶瓷器血、電視機等容易受損或戶主特別吩咐不要弄花的傢俱加上防護軟熱, 日本的搬 運工人則把大小雜物都小心翼翼地妥善包裹, 唯恐弄損, 連一杯一碟都分別以白報紙逐一包好, 在中 國人看來, 這種謹小慎微的做法簡直多此一舉, 反之, 日本人則認為中國人在這方面比較粗枝大葉。 不少中國人自傲不拘小節, 但也有人認為這種不拘小節的心態正是造成中國產品質量粗糙的原因之

\section{9. 《醬缸文化・村八分文化》}

有論者形容中國文化是一個醬缸, 在惡幣驅逐良幣的效應下, 中國人在醬缸中互相習染, 不少惡 習例如骿、亂、吵、窩裡鬥、死不認錯等一代一代相傳下去。但也有論者認為這種醬缸文化其實像武 俠小說中的吸星大法, 包容力十分巨大, 無論是怎麼樣的異類文化, 一旦給吸進醬缸之中, 都會漸漸 受到同化。論者認為這也是為什麼中華民族在過去的歷史中, 屢次受過異族統治而依然屹立不倒的原 因。也有人分析說, 中國文化也有優良的一面, 只是在醬缸中醬得太久, 思想和判斷, 甚至視野都受 到醬缸的污染, 致使道德標準和價值觀念出現混亂。在鄧小平倡議的先讓一部份人富起來的政策下, 獨善其身壓倒了兼善天下, 同而不和的小人壓倒了和而不同的君子; 各家自掃門前雪壓倒了老吾老以 及人之老; 寧我負天下人, 莫天下人負我壓倒了先天下之憂而憂; 巧取豪奪遂成為了待人處事的最高 準則。不少人對中國自滿清末年開始的長期積弱歸处於中國人對傳統文化的自我陶醉, 在受到西方列 強船堅炮利衝擊下方才醒覺。於是自五四運動開始, 激進者以打倒孔家店為口號, 全面否定傳統文 化。

有人說過一個中國人是條龍, 三個中國人是條蟲, 說明中國人擅於個人鑽營, 但缺乏團結精神, 幾個中國人走在一起, 大家都自以為是, 往往各持己見, 最終各行其是。相對於中國人而言, 一個日 本人是條蟲, 三個日本人是條龍, 說明日本人難以發揮個人力量, 但易於團結, 而且力量驚人。一些 學者認為造成這種現象的主要原因是日本人普遍受村八分（むらはちぶ）文化影響所致，村八分文化 令大家不願突顯自己, 同時又不希望受到孤立, 遂令跟隨大隊行事成為本能, 間接孕育出集體主義精 神, 也因此而產生了對社會有很大衝擊的內外有別（内と外）現象和催生了欺凌文化（いじめ文化） 這些副產品。在生活圈子中被劃歸為外人的人或族群是不幸的, 這些人會受到歧視甚至排斥。好像自 鎌倉時代 (1185-1333) 開始因在攻城掠地中戰敗而成為奴隸, 後來漸次被區分為穢多、非人的部落 民, 時至現在依然在升學、就業、結婚等事情上受到一定程度的歧視。2011 年 3 月 11 日東北大地震 後, 因核電廠洩漏幅射而不得不他遷的福島縣居民也得像當年受原子彈轟炸後, 曾曝露在輻射中的一 
些人一樣, 忍受其他人投來的鄙視眼光。内外有別和欺凌現象在一般辦公室和學校裡也很常見, 在公 司裡被投閒置散的「空際族」其實也是被視為外人的一類。在學校裡, 大家都盡量避免自己成為受孤 立的一個而拼命尋找待罪羔羊, 這對常常自傲是單一民族的日本人來說, 内外有別和欺凌現象無疑是 個莫大的諷刺。

中國人說一山不能藏二虎, 還有兩虎雙鬥, 必有一傷, 在說明了老虎獨立的個性, 如果以老虎來

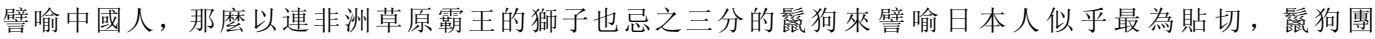
結, 但一旦被逐離群, 命運堪虞。

\section{0. 《入郷問禁》}

俗語說, 一處鄉村一處例, 入鄉不問禁, 很容易觸犯了當地的禁忌而產生誤會。不會送鐘給人作 慶典賀禮幾乎是大多數中國人的共識, 這是喜歡送鐘給別人作新居入伙或公司新張誌慶賀禮的日本人 不明所以的。其他好像賭徒忌給別人拍肩膀, 因為這會導致輸錢; 年初一忌以掃帚掃地, 因為會把好 運掃走; 農曆七月不宜舉行婚禮; 懷孕期間不能搬動傢俱或在牆上鍾釘, 因為會導致流產等中國人的 忌諱都是日本人難以理解的。其實日本人的忌諱絕不比中國人少, 以數字來說, 日本人認為 4 和 9 都 是不吉利的數字, 因為諧音跟「死」和「苦」一樣, 一些醫院不設 42 號病房或病床, 有些甚至連 4 、 24、44 也視為不吉而故意略去, 其中 24 更被視為「二重死」（にじゅうし）, 屬大凶。日本人忌帶 有根植物前往探病, 因為有根即「根付 $く 」$, 令人聯想到久病臥床的「寝付 $<」$, 大大不吉。此外, 由於習俗上在入殮的時候要把死者遺體依佛祖釋迦牟尼圓叔時一樣頭部向北, 所以睡覺的時候枕頭也 忌向北。到日本人家裡作客, 進入屋裡的時候, 切忌踏在門檻上, 因為門檻象徵戶主的家和家人, 踏 在人家門檻上有踐踏別人之意。上世紀 80 年代, 日本企業在海外投資蔚然成風, 曾經有打算在香港購 地建廠的某日本公司在簽約的一天改變主意, 寧願遭沒收訂金和賠款也拒絕簽約, 理由是當天是「仏 滅」，萬事不宜云。夏天 $7 、 8$ 月的土用期間不能動土也是不可不知的日本人禁忌之一。

\section{1. 《矛盾・衝突・融合》}

日本在 1968 年跨越西德, 成為全球第二經濟大國, 其後 20 餘年持續增長, 令日本國力大增。時 移勢易, 上世紀末開始, 中國在經濟發展上突飛猛進, 終於在 2010 年第 2 季取代了日本, 成為僅次於 美國的第二大經濟體系。在此消彼長和激烈競爭底下, 中日兩國在政治、經濟甚至文化等多個領域頻 頻發生摩擦, 例如那邊廂日本指中國輸日的餃子混有農藥, 這邊廂中國則驗出日本輸華的化妝品中含 禁用物質。在年前 (2010 年) 釣魚台海域的撞船事件中, 日本高調拘留中國漁船船長引起中國強烈反 應, 除要求日本馬上無條件釋放船長之外, 更一度限制稀有土壤出口作為報復。兩國關係, 由 1972 年 宣佈復交時開始直至現在, 在各有所需和互相競爭底下, 時而親近, 時而緊張, 這些情況究竟有多少 是彼此並不了解對方的文化而引致的呢? 中日兩國民族都各有本身的文化, 無論在價值觀、行為規 範、風俗習慣等方面都有很大的差別甚至對立。不過, 如果把文化不同作借口來掩飾各自的短處, 衝 突將永無止境, 遑論消弭矛盾。 